\title{
Drug resistant microorganisms isolated from the cases of Otitis media in a tertiary care hospital
}

\author{
Kala Yadhav M.L. ${ }^{1}$, Veena M. ${ }^{2}$ \\ ${ }^{1}$ Dr. Kala Yadhav M. L., Professor, ${ }^{2}$ Dr. Veena M, Postgraduate, both authors are affiliated with Department of \\ Microbiology, Bangalore Medical College and Research Institute, Karnataka, India.
}

Corresponding Author: Dr. Veena M, Postgraduate in Department of Microbiology, Bangalore Medical College and Research Institute, Karnataka, India. Email- mveena42@gmail.com

\begin{abstract}
Introduction: Otitis media $(\mathrm{OM})$ is a major health problem worldwide. WHO has reported hearing impairment in 42 million people (above 3 years) globally was mainly caused by OM. The prevalence rate of ASOM in India is around 17$20 \%$ and CSOM is $7.8 \%$. Objective: The aim was to determine microbiological profile of organisms causing otitis media and to assess their antibiotic susceptibility pattern from our geographical area. Methods: This is a prospective study of 148 clinically suspected cases of OM (ASOM \& CSOM). Samples were cultured and antibiotic susceptibility test was performed as per CLSI guidelines. Result: Out of 148 cases of OM, the male to female ratio was 1:1.17,97(65.54\%) were culture positive and 51(34.45\%) culture negative. Among bacterial pathogens, Staphylococcus aureus was the commonest organism isolated (31.57\%) followed by Pseudomonas aeruginosa (20\%). Of the staphylococcus aureus isolates, 14(46.66\%) were MRSA. Majority of Staphylococcus aureus isolates were found resistant to multiple antibiotics including Penicillin G (96.6\%) \& Azithromycin (76.6\%). High level of resistance observed in the isolates of Pseudomonas aeruginosa [Imipenem (31.57\%) and Ceftazidime (52.63\%)]. Multidrug resistance was also found in Enterobactericeae, showing resistance to Cotrimoxazole (76.19\%) \& Amoxicillin-clavulanic acid (66.66\%). GNNF was found $100 \%$ sensitive to imipenem and 50\% resistant to ciprofloxacin. Conclusion: Emergence of resistance strains among the isolates of $\mathrm{OM}$ has led to treatment failure leaving narrow spectrum of treatment options. Therefore, knowledge of microorganism profile and their antibiotic sensitivity pattern is important for the management of the disease and to prescribe empirical antibiotics for successful treatment.
\end{abstract}

Key words: Otitis Media, CSOM, ASOM, Antibiotic resistance/ sensitivity

\section{Introduction}

Otitis media (OM) is defined as inflammation of middle ear that may present with recurrent ear discharges through a tympanic perforation [1]. Acute suppurative otitis media (ASOM) is an acute phase ( $<3$ weeks) of otitis media, characterized by inflammation and presence of fluid in middle ear which is more common in children. Chronic suppurative otitis media (CSOM) is a recurrent or persistent otorrhoea through a perforated tympanic membrane for more than 3 weeks.

It is a major health problem and occurs with a high incidence and prevalence in both developed and developing countries. WHO has reported that hearing impairment in 42 million people (above 3 years) globally was mainly caused by OM [2]. The prevalence rate of ASOM in India is around $17-20 \%$ and CSOM is

Manuscript received: $10^{\text {th }}$ October 2018

Reviewed: $20^{\text {th }}$ October 2018

Author Corrected: $26^{\text {th }}$ October 2018

Accepted for Publication: $30^{\text {th }}$ October 2018
$7.8 \%$ [3]. The chief routes by which infection occurs is the eustachian tube and the perforation of tympanic membrane. Both Gram positive and Gram-negative organisms are involved in the pathogenesis of otitis media. Due to increased and irrational use of wide-spectrum antibiotics in the community, drug resistance has become very common. Hence, microbial culture and antibiotic sensitivity is very essential in appropriate management of otitis media and thus prevents the emergence of resistant bacterial strains.

The study was carried out to determine microbiological profile of the organisms causing otitis media and to assess their antibiotic susceptibility pattern to commonly used antibiotics from our geographical area, which aids in the initiation of accurate therapy for effective management and prevents the emergence of drug resistance. 


\section{Original Research Article}

\section{Materials and Methods}

Type \& place of study: The prospective study was carried out at the department of microbiology on clinically suspected cases of otitis media (ASOM \& CSOM) attending OPD of Bowring and Lady Curzon Hospital, a tertiary care hospital for a period of 2 years from January 2016 to January 2018.

Sample collection: The ear discharge was collected aseptically from a total of 148 clinically suspected cases of OM with the aid of an aural speculum, prior to the instillation of any topical medication. Clinical diagnosis was made by a consultant Otorhinolaryngiologist.

Inclusion criteria: Patients of all the age groups, irrespective of gender and immune status with the history of otalgia, itching and tinnitus along with unilateral or bilateral otorrhea were included in the study.

Exclusion criteria: Patients on local or systemic antibiotics, antifungals or corticosteroids and discharge with intact ear drum (otitis externa) were excluded from the study.

Sampling method: Ear discharge collected with 2 sterile swabs was immediately transported to microbiology lab for the isolation and identification of microorganisms. One swab was used to make a smear on clean grease-free glass slide for Gram's stain examination and direct microscopy of specimen in $\mathrm{KOH}$ for fungal examination. Another swab was used for culture on chocolate agar, MacConkey's agar and on SDA which was then incubated for 24 hours at $37^{\circ} \mathrm{C}$.

The isolates were identified by using colony morphology and standard biochemical tests. Antibiotic susceptibility test was performed by Kirby-Bauer disk diffusion method on Mueller-Hinton agar plate as per CLSI guidelines using commercially available antibiotic discs (Hi Media, Bangalore). Various antibiotics tested are as follows;

Disks tested for Gram negative bacilli: AmoxicillinClavulanic acid $(20 / 10 \mu \mathrm{g})$, Ampicillin / Sulbactam $(20 / 10 \mu \mathrm{g})$, Amikacin $(30 \mu \mathrm{g})$, Aztreonam $(30 \mu \mathrm{g})$,

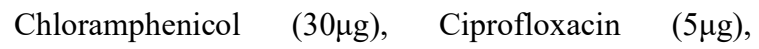
Cotrimoxazole $(1.25 / 23.75 \mu \mathrm{g})$, Imipenem $(10 \mu \mathrm{g})$, Piperaciliin-Tazobactum $\quad(100 / 10 \mu g), \quad$ Ceftazidime $(30 \mu \mathrm{g})$ and Cefepime $(30 \mu \mathrm{g})$. Colistin $(10 \mu \mathrm{g})$ and additional drug Polymyxin-B $(300 \mu \mathrm{g})$ for P. aeruginosa.

Disks tested for Gram positive cocci: Penicillin G (10

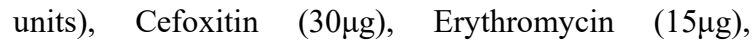
Clindamycin $(2 \mu \mathrm{g})$, Cotrimoxazole $(1.25 / 23.75 \mu \mathrm{g})$, Doxycycline $(30 \mu \mathrm{g})$, Ciprofloxacin $(5 \mu \mathrm{g})$, Gentamicin $(10 \mu \mathrm{g})$, Linezolid $(30 \mu \mathrm{g})$, Vancomycin $(30 \mu \mathrm{g})$, Cefuroxime $(30 \mu \mathrm{g})$, Chloramphenicol $(30 \mu \mathrm{g})$ and Azithromycin $(15 \mu \mathrm{g})$.

Statistical analysis was carried out using pie charts, tables and bar graphs.

\section{Results}

Out of total 148 clinically suspected cases of OM, 68(45.94\%) were males and $80(54.05 \%)$ were females as shown in the figure 1. Male to female ratio was 1:1.17 showing female predominance. Majority of the cases were reported from the age group 0 -10years $(22.68 \%)$ as shown in table 1 .

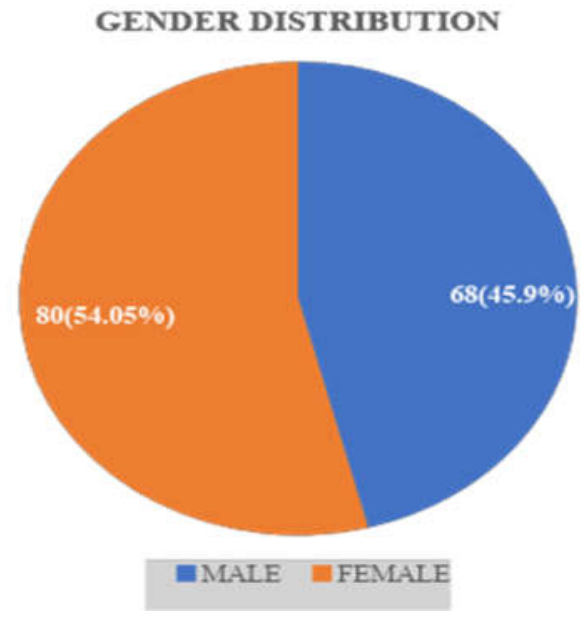

Figure-1: Gender distribution of the cases 


\section{Original Research Article}

Table-1: Age wise distribution of clinically suspected and culture positive cases

\begin{tabular}{|c|c|c|c|c|}
\hline Age (years) & $\begin{array}{c}\text { Suspected cases } \\
(\mathbf{n = 1 4 8})\end{array}$ & Percentage (\%) & $\begin{array}{c}\text { Total culture } \\
\text { positive (n=97) }\end{array}$ & Percentage (\%) \\
\hline$<10$ & 30 & $20.27 \%$ & 22 & $22.68 \%$ \\
\hline $11-20$ & 28 & $18.91 \%$ & 19 & $19.58 \%$ \\
\hline $21-30$ & 25 & $16.89 \%$ & 17 & $11.52 \%$ \\
\hline $31-40$ & 22 & $14.86 \%$ & 11 & $12.37 \%$ \\
\hline $41-50$ & 17 & $11.48 \%$ & 12 & $12.37 \%$ \\
\hline $51-60$ & 14 & $9.45 \%$ & 12 & $4.12 \%$ \\
\hline$>60$ & 12 & $8.10 \%$ & 4 & $12 \%$ \\
\hline
\end{tabular}

Of 148 samples received 97(65.54\%) were culture positive and 51(34.45\%) were culture negative. Out of 97 culture positive cases, 95(97.93\%) were pure bacterial isolates and 2(1.35\%) were pure fungal isolates (Aspergillus and Candida species). Polymicrobial isolation was not seen in our study.

Among bacterial pathogens, Staphylococcus aureus was the commonest organism isolated 30(31.57\%) followed by Pseudomonas aeruginosa 19(20\%), Klebsiella pneumoniae 18(18.9\%), Citrobacter spp 11(11.5\%), E. coli 8(8.4\%), Proteus 5(5.2\%) and GNNF 4(4.2\%) as shown in the figure 2.

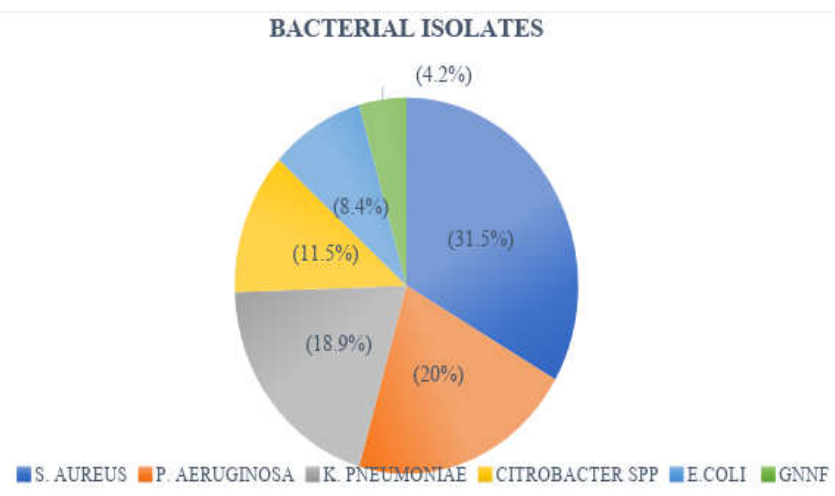

Figure- 2: Distribution of bacterial isolates.

Of total staphylococcus aureus isolates, 14(46.66\%) isolates were Methicillin resistant Staphylococcus aureus (MRSA) showing resistance to cefoxitin. Majority of Staphylococcus aureus isolates were found resistant to multiple antimicrobial agents including Penicillin G (96.6\%), Azithromycin (76.6\%), Cotrimoxazole (76.6\%) and Erythromycin (60\%) as shown in the figure 3. However they were sensitive to Vancomycin (96\%) and Linezolid (93\%).

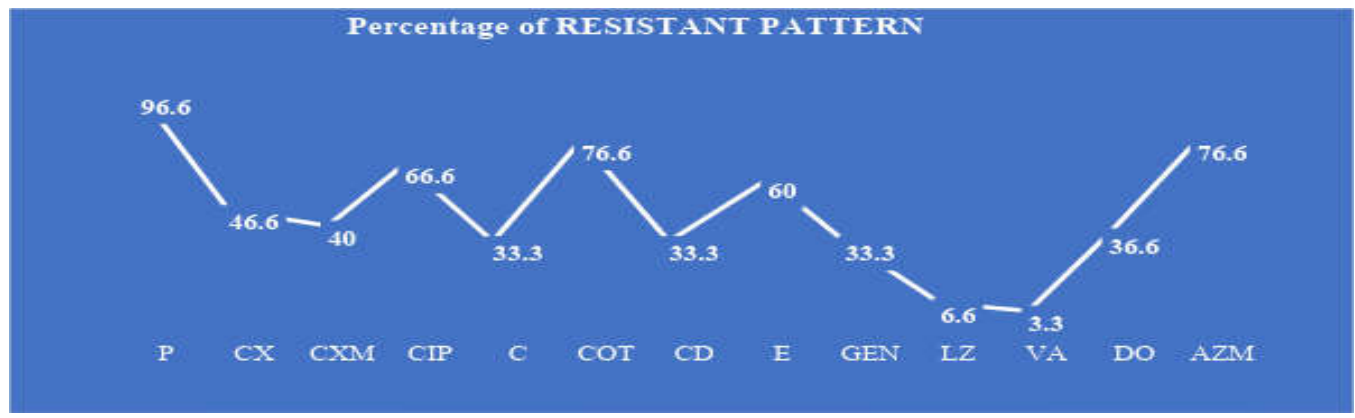

Figure-3: Antibiotic resistant pattern of Staphylococcus aureus (n=30).

P: Penicillin(n=29), CX: Cefoxitin(n=14), CXM: Cefuroxime (n=12), CIP: Ciprofloxacin (n=20), C: Chloramphenicol $(n=10)$, COT: Cotrimoxazole $(n=23)$, CD: Clindamycin( $n=10)$, E: Erythromycin $(n=18)$, GEN: Gentamicin( $n=10)$, LZ: Linezolid ( $n=2)$, VA: Vancomycin(n=1), DO: Doxycycline ( $n=11)$, AZM: Azithromycin ( $n=23)$. 


\section{Original Research Article}

High level of resistance was observed in the isolates of Pseudomonas aeruginosa. It was found resistance to Imipenem $(31.57 \%)$ and Ceftazidime (52.63\%), however it was found sensitive to Piperacillin-tazobactam (84\%) and Cefepime (84\%). Multidrug resistance was also found in Enterobactericeae [Klebsiella, E. coli, Citrobacter and Proteus mirabilis], showing resistance to Cotrimoxazole (76.19\%), Amoxicillin-clavulanic acid (66.66\%), Chloramphenicol (54.75\%), Ampicillin (42.85\%) and Ciprofloxacin (38.09\%). None of the isolates were found resistant to Colistin and Polymixin B.

GNNF was $100 \%$ sensitive to imipenem. But $50 \%$ were resistant to ciprofloxacin as shown in the table 2.

Table- 2: Antibiotic resistant pattern of Gram Negative isolates.

\begin{tabular}{|c|c|c|c|c|c|c|c|c|c|c|c|c|}
\hline \multicolumn{8}{|c|}{ Antibiotic resistance pattern (\%) } \\
\hline $\begin{array}{c}\text { Gram negative } \\
\text { isolates }\end{array}$ & AMC & A/S & PIT & COT & CIP & AT & CPM & AK & C & IPM & CAZ & LE \\
\hline $\begin{array}{c}\text { P. aeruginosa } \\
(n=19)\end{array}$ & 84.2 & 84.2 & 15.7 & - & 26.3 & 42.1 & 15.7 & 36.8 & - & 31.5 & 52.6 & 26.3 \\
\hline $\begin{array}{c}\text { K. pneumoniae } \\
(n=18)\end{array}$ & 88.8 & 55.5 & 27.7 & 66.6 & 38.8 & 44.4 & 44.4 & 22.2 & 61.1 & 50 & - & - \\
\hline $\begin{array}{c}\text { Citrobacter spp } \\
(n=11)\end{array}$ & 63.6 & 45.4 & 27.2 & 63.6 & 54.5 & 45.4 & 45.4 & 54.5 & 72.7 & 54.5 & - & - \\
\hline $\begin{array}{c}\text { E. coli } \\
(\mathrm{n}=8)\end{array}$ & 25 & 12.5 & 0 & 62.5 & 0 & 37.5 & 12.5 & 25 & 0 & 0 & - & - \\
\hline $\begin{array}{c}\text { Proteus spp } \\
(\mathrm{n}=5)\end{array}$ & 60 & 40 & 0 & 80 & 60 & 20 & 20 & 0 & 80 & 60 & - & - \\
\hline $\begin{array}{c}\text { GNNF } \\
(\mathrm{n}=4)\end{array}$ & 75 & 100 & 0 & 100 & 50 & 25 & 25 & 25 & 75 & 25 & - & - \\
\hline
\end{tabular}

GNNF: Gram negative non-fermenters, AMC: Amoxycillin-clavulanic acid, A/S: Ampicillin-sulbactam, PIT: Piperacillin- Tazobactam, COT: Cotrimoxazole, CIP: Ciprofloxacin, AT: Aztreonam, CPM: Cefepime, AK: Amikacin, C: Chloramphenicol, IPM: Imipenem, CAZ: Ceftazidime, LE: Levofloxacin.

\section{Discussion}

Otitis media is the most common ear disease encountered in day to day clinical practice. Untreated ASOM cases, may go into recurrent otorrhoea, leading to CSOM which may end up in irreversible local destruction of middle ear structures causing deafness and intracranial complications if not treated promptly [4].

Early microbiological diagnosis becomes very important in the cases of otitis media, as it helps for prompt and effective treatment to avoid its complications, as well as to know common pathogens associated with the disease in that locality[1].

In this study, conducted at a tertiary care hospital of Bangalore, we looked for the two years bacterial antibiotic sensitivity profile of otitis media cases.

A study by Prakash $M$ et al., have shown female predominance of CSOM [5]. Our study showed female predominance of the disease with male to female ratio
1:1.17. On the contrary, Gopi A et al., and Afolabi OA et al., showed male predominance [6,7]. Geographical variations may be the reason for these differences in the results.

In our study, prevalence of otitis media was the highest in first decade of life. This finding corresponds with a studied by Bhumbla $\mathrm{U}$ et al. and Kumar R et al. [8,9]. Short and wide eustachian tube, predisposition to cold, adenoiditis, URTI and more prone for trauma may be the reasons for highest incidence in this age group. And may also be because we included ASOM in our study which is common in children. These results are in contrary with the work published by Garima et al., where disease was more prevalent in second and third decade [10].

The culture positivity rate in present study was $65.54 \%$. Other studies have showed varying culture positivity rates from $73.45 \%$ to $91.18 \%[1,11]$. Out of culture positive cases, bacteria was isolated from $97.93 \%$ and 


\section{Original Research Article}

fungus was isolated from $1.35 \%$ samples. This is in consistence with a study by Agrawal A et al., in which $80 \%$ were bacterial isolates and only $2.4 \%$ were fungal isolates i.e. Candida and Aspergillus species [12].

Culture negativity ranging from $12.6 \%$ to $26.54 \%$ were seen in different studies carried out in India $[1,13]$. Comparatively $34.4 \%$ of culture negativity was found in our study.

This might be because, the study was conducted in tertiary care hospital, patients usually come to us after consulting local medical personal and having taken multiple or incomplete antibiotic courses which might have lead to sterile culture. And also, these infections may have been caused by the organisms which were not looked for in our study such as anaerobes.

We found that the most common pathogen causing otitis media in our locality was Staphylococcus aureus followed by Pseudomonas aeruginosa. Similar results were found in the Indian studies conducted by Prakash $\mathrm{R}$ et al. and Agrawal A et al.with 48.69\% and 37.6\% prevalence of Staphylococcus aureus and 19.89\% and $32.8 \% \mathrm{P}$. aeruginosa respectively $[14,12]$.

Similar findings have been found in abroad studies as well [15]. However, others reported that Pseudomonas aeruginosa was the commonest isolated microorganism in CSOM patients [16,17,18]. Coliforms such as Klebsiella pneumoniae and E. coli were also isolated which is in agreement with studies by different authors $[7,18]$.

Staphylococcus isolates showed resistance to multiple antimicrobial agents. Several studies have reported the similar findings $[1,19,20]$. MRSA rate was as high as $46.66 \%$. Such high level of MRSA from cases of otitis media is a matter of concern as MRSAs are resistant to beta lactams, cephalosporins, beta lactamase inhibitors leaving narrow treatment options. Recent studies by different authors have reported MRSA ranging from $29 \%$ to $83.3 \%[21,22]$.

Resistance with ciprofloxacin was $66.66 \%$ in our study. In contrary to some studies where the Staphylococcus specie's sensitivity with ciprofloxacin was higher ranging from $\quad 83.0 \%-95.0 \% \quad[23,24,25]$. Vancomycin \& linezolid were $96 \%$ and $93 \%$ sensitive respectively and also against MRSA positive, thus making these agents as the drug of choice for same.

Pseudomonas aeruginosa showed $84 \%$ sensitivity with piperacillin/tazobactam, and $68 \%$ sensitivity with imipenem in our study. Tahir et al. observed 95\% sensitivity with imipenem, and $100 \%$ sensitivity with piperacillin/ tazobactam [24]. Resistance with quinolones was $26.31 \%$ in our study. These observations are in contrast to the other studies showing higher sensitivity of $90-92 \%$ with least resistance rate [24,25]. The increasing resistant trend with quinolones may be due to number of factors including injudicious use, inappropriate doses, and easy accessibility and developing enzymatic resistance of organisms.

In our study, $42.85 \%$ imipenem resistance strains of Enterobacteriaceae were found. Resistance with ciprofloxacin was $38.09 \%$.

Limitations: Our study had few limitations due to lack of resources. We had not looked for mycoplasma, chlamydia and anaerobic microorganisms in our study. Antifungal susceptibility testing and genotypic methods for detection of resistance could not perform. In spite of all these, our study highlights the common microorganisms associated with $\mathrm{OM}$ and their resistance pattern of our locality which was not documented previously.

\section{Conclusion}

Otitis media is still a problem among the children of first decade. It is more prevalent among females than the males, the commonest etiological agents implicated being Staphylococcus aureus followed by pseudomonas aeruginosa. Some studies have shown the emergence ofhigh resistance organisms isolated from the cases of ASOM \& CSOM $[1,9,20]$.

Similarly in our study, high level of resistance to various commonly used antimicrobial agents was observed in $\mathrm{OM}$ cases. And emergence of these resistance strains has led to treatment failure leaving narrow spectrum of treatment options.

Knowledge of microorganism profile causing ear discharge and their antibiotic sensitivity pattern is important. This study provides the information about common organism isolated and its antibiotic susceptibility pattern in our locality which aids in management of the disease i.e. whether to start antibacterial agents prescribing empirical antibiotics or antifungal agents for effective therapy. And to prescribe empirical antibiotics for successful treatment which helps in reduction of treatment costs and thus minimizing its complications and emergence of resistant strains. Absence of mixed culture again is a sign of good prognosis.

Findings: Nil; Conflict of Interest: None initiated Permission from IRB: Yes 


\section{Original Research Article}

\section{References}

1. Kashyap S, Pandey A, Thakuria B, Saxena AK, Asthana AK, Madan M. Resistant Microorganisms Isolated from Cases of Chronic Suppurative Otitis Media: A Therapeutic concern. National Journal of Laboratory Medicine 2017 Apr; 6(2): MO01-MO06. DOI: 10.7860/NJLM/2017/22022:2211.

2. Kumari MS, Madhavi J, Krishna NB, Meghanadh KR, Jyothy A. Prevalence and associated risk factors of otitis media and its subtypes in South Indian population. Egyptian Society of Ear, Nose, Throat and Allied Sciences 2016;17:57-62. Doi: http://dx.doi.org/10. 1016/j. ejenta.2016.04.001

3. Lazo-Saens JG, Galvan-Aguilera AA, MartinazOrdaz VA, Velasco-Rodriguez VM, Nieves-Renteria A, Rincon-Castaneda C. Eustachian tube dysfunction in allergic rhinitis. OtolaryngolHeadNeck Surg. 2005; 132:626-629. doi: https://doi.org/10. 1016/j.otohns. 2005.01 .029

4. Shrestha BL, Amatya RCM, Shrestha I, Ghosh I. Microbiological profile of chronic suppurative otitis media. Nepalese Journal of ENT Head and Neck Surgery 2011;2(2)6-7.

5. Prakash M, Lakshmi K, Anuradha S, Swathi GN. Bacteriological profile and their antibiotic susceptibility pattern of cases of chronic suppurative otitis media. Asian J Pharm clin res. 2013;6(suppl 3):210-12.

6. Gopi A, Kottilaveetil HT, Khair SMU, Harindranath D. Bacteriological profile of chronic suppurative otitis media cases at a tertiary care centre in Karnataka. J Evolution Med Dent Sci. 2016;5(14):623-626. DOI: 10. 14260/jemds/2016/142.

7. Afolabi OA, Salaudeen AG, Ologe FE, Nwabuisi C, Nwawolo CC. Pattern of bacterial isolates in the middle ear discharge of patients with chronic suppurative otitis media in a tertiary hospital in North central Nigeria. African Health Sciences 2012;12(3):362-368. DOI: http://dx.doi.org/10.4314/ahs.v12i3.18.

8. Bhumbla U, Paul S, Mathur DR, Gyaneshwari. Bacteriological Study of CSOM and their Changing Pattern of Antibiotic Sensitivity and Resistance. Int.J.Curr.Microbiol.App.Sci 2016;5(10):282-288. DOI: http://dx.doi.org/10.20546/ijcmas.2016.510.031.

9. Kumar R. Acute Otitis Media bacteriological study and drug sensitivity pattern. J Evolution Med Dent Sci 2013 Sep 23;2(38)7297-7301.
10. Garima, Chaurasia D, Poorey VK. Antimicrobial susceptibility pattern of bacterial isolates from chronic suppurative otitis media patients in Central India. Indian J Microbiol Res 2016;3(4):373-382. DOI: 10.18231/ 2394-5478.2016.0006

11. Srivastava A, Singh RK, Varshney S, Gupata P, Bist SS, Bhagath S, et al. Microbiological evaluation of an active tubotympanic type of CSOM. Nepalese J ENT Head Neck Surg. 2010;1(2):14-16.

12. Agrawal A, Kumar D, Goyal A, Goyal S, Singh N, Khandelwal G. Microbiological profile and their antimicrobial sensitivity pattern in patients of otitis media with ear discharge. Indian J Otol2013;19:5-8.

13. Fatma AA, Assiry S, Siraj MZ. Microbiological evaluation and aspects on management of chronic suppurative otitis mediain Riyadh. Indian J Otol1998; 4:115-20.

14. Prakash R, Juyal D, Negi V, Pal S, Adekhandi S, Sharma M, Sharma N. Microbiology of Chronic Suppurative Otitis Media in a Tertiary care setup of Uttarakhand state, India. N AM J Med Sci 2013 Apr; 5(4): 282-287. DOI: 10.4103/1947-2714.110436.

15. Nia KM, Sepehri G, Khatmi H, Shakibaie MR. Isolation and Antimicrobial Susceptibility of Bacteria from Chronic Suppurative Otitis Media Patients in Kerman, Iran. Iran Red Crescent Med J 2011 Dec; 13 (12): 891-894.

16. Kumar H, Seth S, Bacterial and Fungal study of 100 cases of Chronic Suppurative Otitis Media. JCDR 2011; 5:1224-27.

17. Shyamla R, Reddy SP, the study of bacteriological agents of Chronic Suppurative Otitis Media-aerobic culture and evaluation. J Micro biol Biotechno Res 2012;2:152-62.

18. Mansoor T, Musani MA, Khalid G, Kamal M. Pseudomonas aeruginosa in Chronic Suppurative Otitis Media: Sensitivity spectrum against various antibiotics in Karachi. J Ayub Med Coll Abbottabad 2009; 21: 120-23.

19. Malkappa SK, Kondapaneni S, Surpam RB, Chakraverti TK. Study of aerobic bacterial isolates and their antibiotic susceptibility pattern in Chronic Suppurative Otitis Media. Indian J Otol2012;18:136-39. 


\section{Original Research Article}

20. Hegde MC, Bhat GK, Sreedharan S, Ninan GP. Bacteriological study of tubotympanic type of Chronic Suppurative Otitis Media. Indian J Otol 2005; 11: 13-16.

21. Khatoon A, Rizvi M, Sultan A, Khan F, Sharma M, Shukla I et al. Chronic Suppurative Otitis Media: a clinic-microbiological menance. International $\mathrm{J}$ Res Med Sci 2015; 3(8):1932-36.

22. Rejitha IM, Sucilathangam G, Kanagapriya M. Microbiologic profile of chronic suppurative otitis media in a tertiary care hospital. International J Sci Res $2014 ; 3(2): 474-76$.
23. Nia KM, Sepehri G, Khatmi H, Shakibaie MR. Isolation and antimicrobial susceptibility of bacteria from chronic suppurative otitis media patients in Kerman, Iran. Iran Red Crescent Med J 2011;13:891-4.

24. Tahir M, Jawaid A, Abdullah A, Najam MA. Bacterial culture and sensitivity in active chronic otitis media: 500 cases in combined military hospital Rawalpindi. Pak J Otolaryngol2012;28:56-8. 16.

25. Madana J, Yolmo D, Kalaiarasi R, Gopalakrishnan S, Sujata S. Microbiological profile with antibiotic sensitivity pattern of cholesteatomatous chronic suppurative otitis media among children. Int J Pediatr Otorhinolaryngol2011;75:1104-8.

\section{How to cite this article?}

Kala Yadhav M.L, Veena M. Drug resistant microorganisms isolated from the cases of Otitis media in a tertiary care hospital. Trop J Path Micro 2018; 4(6):466-472.doi:10.17511/jopm.2018.i06.08. 